\title{
Ischaemic colitis
}

\author{
ADRIAN MARSTON, MURRAY T. PHEILS, M. LEA THOMAS, AND B. C. MORSON \\ From the Department of Surgical Studies, The Middlesex Hospital, London, \\ the Department of Surgery, St. Peter's Hospital, Chertsey, the Department of \\ Radiology, St. Thomas's Hospital, London, and the Department of Pathology \\ and the Research Department, St. Mark's Hospital, London
}

EDITORIAL SYNOPSIS This important paper brings a conceptual unity to the clinical problems of ischaemia attacking the gut and describes the three syndromes which may occur. On the basis of post-clinical and experimental work a classification of ischaemic colitis into gangrenous, stricturing, and transient forms is proposed. It is suggested that ischaemia of the colon, occurring in the same age group and from the same causes as myocardial infarction, accounts for certain cases of 'segmental' colitis, particularly those involving the splenic flexure.

A possible cause of acute structural change in the colon is deprivation of arterial blood. Episodes of ischaemia involving the heart or brain are common enough, and it would be surprising if similar events did not occasionally take place in the intestine, particularly the large intestine, whose blood supply is comparatively precarious. Infarcts of the colon have been described from time to time (Thomson, 1948; Engelhardt and Jacobson, 1956; McCort, 1960; Marston, 1962a; Marshak, Maklansky, and Calem, 1965; Varga and Currie, 1965), usually as single case reports or in very small series. Because ischaemia of the bowel results in immediate bacterial invasion, these cases present as an attack of acute 'colitis' of unexplained origin. Many examples of colitis have been reported which do not fit into any established clinical category and in which the pathology is unlike that of Crohn's disease or idiopathic proctocolitis (ulcerative colitis) (Brownlee, 1951; Boreham, 1957; Kellock, 1957; Killingback and Williams, 1961; Hannan, Jackson, and Pipik, 1964; McGovern and Goulston, 1965), and it is likely that some of these have a vascular basis.

There are three possible outcomes of sudden withdrawal of blood supply to a loop of intestine (Marston, 1964), which depend on the size of the occluded vessels, the duration of the occlusion, the efficiency of the collateral circulation, and the bacteria present within the lumen.

If the length of bowel involved is greater than the marginal and intramural vessels can supply, then necrosis, sloughing, and death from general peritonitis will ensue (Niederstein, 1906).
A situation sometimes occurs in which just enough blood is supplied to prevent complete death of the intestine, but which is at the same time insufficient for the needs of the damaged mucosa. A combination of necrosis and bacterial invasion takes place. This results in the formation of a variable pathological picture which may include muscular atrophy or hypertrophy, fibrosis, giantcell systems, and the appearance of strictures (Klein, 1921; Pope and O'Neal, 1956; Wolf and Marshak, 1956; Wang and Reeves, 1960; Reeves and Wang, 1961).

If only a small length of bowel is involved, or if the blocked vessel is adequately bypassed by collaterals, transient ischaemia is followed by vasodilatation and complete healing, and no permanent lesion occurs (Boley, Schwartz, Lash, and Sternhill, 1963). Turnover of the mucosal cells is very rapid, and even severe ischaemic damage can be repaired within hours or days (Cameron and Khanna, 1959; Glotzer, Villegas, Anakayama, and Shaw, 1962).

Study of reported cases of unexplained acute inflammation of the colon suggests that there are three disease patterns which correspond to these three pathological processes. It is the purpose of this paper to present three groups of cases of acute colitis in which there is clinical, radiological, and pathological evidence for an ischaemic basis. We have named this syndrome 'ischaemic colitis' and suggest that it is a common condition, the management and prognosis of which differ from that of other types of intestinal inflammation. 
TABLE OF CASES

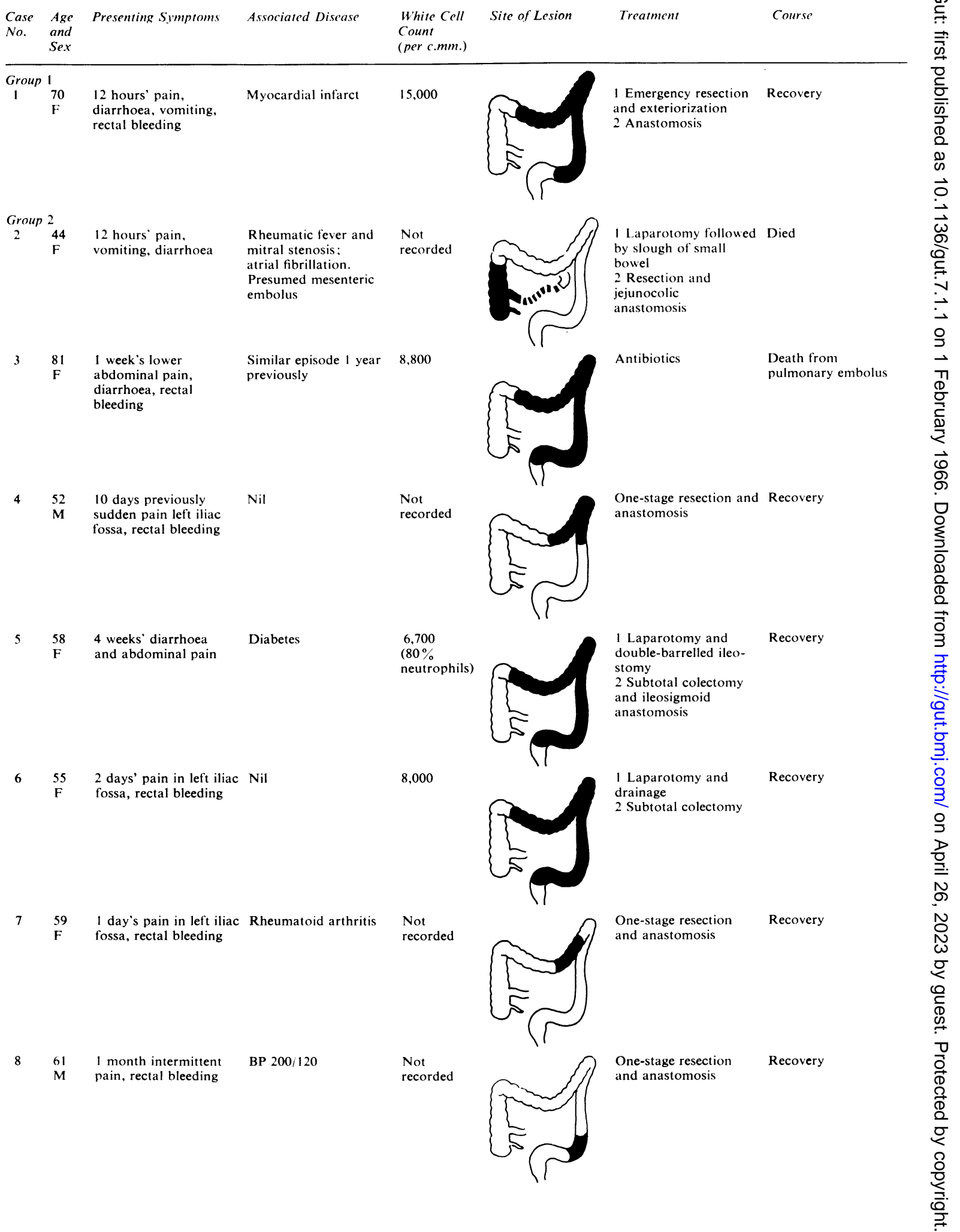


TA B LE OF CASES-continued

\begin{tabular}{|c|c|c|c|c|c|c|c|}
\hline $\begin{array}{l}\text { Case } \\
\text { No. }\end{array}$ & $\begin{array}{l}\text { Age } \\
\text { and } \\
\text { Sex }\end{array}$ & Presenting Symptoms & Associated Disease & $\begin{array}{l}\text { White Cell } \\
\text { Count } \\
\text { (per c.mm.) }\end{array}$ & Site of Lesion & Treatment & Course \\
\hline 9 & $\begin{array}{l}52 \\
M\end{array}$ & $\begin{array}{l}3 \text { months previously } \\
\text { sudden onset of lower } \\
\text { abdominal pain and } \\
\text { rectal bleeding; } \\
\text { episodic pain since }\end{array}$ & $\begin{array}{l}\text { Similar episode } 5 \text { years } \\
\text { previously }\end{array}$ & $\begin{array}{l}\text { Not } \\
\text { recorded }\end{array}$ & & $\begin{array}{l}\text { One-stage resection } \\
\text { and anastomosis }\end{array}$ & Recovery \\
\hline 10 & $\begin{array}{l}67 \\
\mathrm{~F}\end{array}$ & $\begin{array}{l}6 \text { months' rectal } \\
\text { bleeding; occasional } \\
\text { colicky pain and } \\
\text { vomiting }\end{array}$ & Mitral stenosis & $\begin{array}{l}\text { Not } \\
\text { recorded }\end{array}$ & & $\begin{array}{l}\text { One-stage resection } \\
\text { and anastomosis }\end{array}$ & Recovery \\
\hline 11 & $\begin{array}{l}51 \\
\mathrm{~F}\end{array}$ & $\begin{array}{l}1 \text { week previously } \\
\text { sudden abdominal pain } \\
\text { and rectal bleeding }\end{array}$ & Nil & $\begin{array}{l}\text { Not } \\
\text { recorded }\end{array}$ & $\begin{array}{l}\text { Sigmoid colon } \\
\text { (no radio- } \\
\text { graphs) }\end{array}$ & $\begin{array}{l}\text { One-stage resection } \\
\text { and anastomosis }\end{array}$ & $\begin{array}{l}\text { Laparotomy for } \\
\text { adhesive obstruction } \\
9 \text { months later; } \\
\text { recovery }\end{array}$ \\
\hline
\end{tabular}

$1260 \quad 1$ day abdominal pain, Similar episode 1 year No diarrhoea, rectal previously recorded

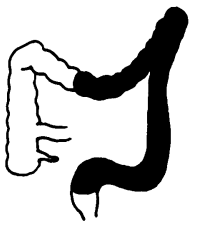

1 Laparotomy and colostomy

2 Resection and caecorectal anastomosis

Uneventful recovery Carcinoma of stomach 4 years later

$1368 \quad 1$ day abdominal pain, Similar episode 2 years

10,500

$(81 \%$ neutrophils)

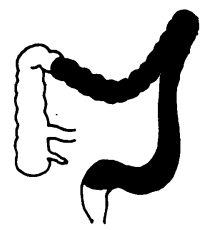

Subtotal colectomy and ileorectal anastomosis

Uneventful recovery

Recovery, barium enema 6 months later normal

14,000
$(80 \%$

$(80 \%$

neutrophils)

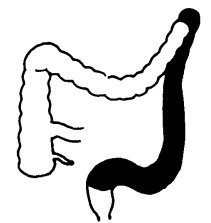

Nil

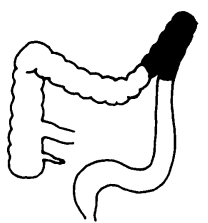

Antibiotics

$(82 \%$

neutrophils) bleeding

Rheumatoid arthritis neutrophils)

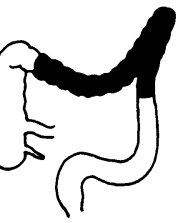

$(82 \%$ neutrophils)
Laparotomy, biopsy

Laparotomy, biopsy

Subsequently developed severe rheumatoid arthritis. Barium enema normal 3 months later 


\section{CLINICAL FEATURES}

This syndrome is characterized by sudden inflammation in the region of the splenic flexure which is followed by gangrene, by progressive stricturing of the bowel, or by resolution.

The clinical features are summarized in the Table. The average age of the 16 patients described is 51 years, the range being 44 to 81 years, with the majority in the sixth and seventh decades. There are 11 women and five men. The presenting symptom in each case was lower abdominal pain of abrupt onset accompanied by vomiting and fever, and all but two patients passed bright red blood and clots per rectum. In all the bowel habit had previously been regular and there was nothing to suggest preexisting idiopathic proctocolitis (ulcerative colitis) or Crohn's disease, but four patients had suffered a similar attack in the past which had cleared up completely. Six patients were not seen until the acute illness had subsided; the remainder were admitted as emergencies. All of these had signs of local peritonitis, and perforated sigmoid diverticulum was the most frequent provisional diagnosis. A polymorph leucocytosis was usual (Table). Two patients were not operated on because they presented in the recovery phase and the real diagnosis was suspected on clinical grounds. The remainder underwent laparotomy. Three illustrative cases will be described.

\section{ILLUSTRATIVE CASES}

GANGRENE OF THE COLON (CASE 1) A married woman, aged 70, was admitted to St. Peter's Hospital, Chertsey, on 17 October 1964, complaining of severe abdominal pain, vomiting, and diarrhoea of 12 hours' duration. She appeared dehydrated and was in great pain. On abdominal examination, there was generalized rigidity, marked tenderness and rebound tenderness on the left side. Bowel sounds were present. On rectal examination there was dark blood on the finger stall. The pulse was 96, blood pressure $190 / 100 \mathrm{~mm} . \mathrm{Hg}$, haemoglobin $10.6 \mathrm{~g} . / 100 \mathrm{ml}$, haematocrit 49 , and white cell count 15,000 per c.mm., with a neutrophil leucocytosis. Serum amylase and electrolytes were normal. A provisional diagnosis of mesenteric vascular occlusion was made and laparotomy carried out six hours after admission.

The abdomen was explored through a right paramedian incision. The peritoneal cavity contained a quantity of seropurulent exudate. An area of gangrenous bowel was discovered between the transverse and descending colon. No obvious vascular occlusion was detected in the mesenteric vessels. The gangrenous area was resected and the proximal and distal ends of bowel exteriorized through separate stab incisions. A blood transfusion was administered. Culture of the peritoneal exudate was sterile. Section of the bowel showed oedema and haemorrhage with confluent necrosis of the mucosa and patchy gangrene of the outer layers.
Following this operation she had a prolonged and stormy course due to myocardial infarction and ischaemic heart disease. She finally became sufficiently fit to undergo mobilization of the ends of the colon and continuity was restored by direct end-to-end anastomosis on 17 December. Her convalescence was again interrupted by cardiac difficulties and some wound infection.

A recent communication from her doctor tells us that she has had a further incident of cardiac infarction.

ISCHAEMIC STRICTURE (CASE 5) A previously healthy woman of 58 was admitted to St. Thomas's Hospital on 7 July 1964, with the complaint of four weeks' weakness, diarrhoea, and anorexia. There had been no rectal bleeding. On examination she was ill and febrile. Thz only notable physical signs were a desquamating rash on the palms, slight generalized abdominal tenderness and distension, and moniliasis of the vulva. The urine contained glucose. Abnormal laboratory data were: white cell count 6,700 per c.mm. ( $80 \%$ neutrophils), E.S.R. $40 \mathrm{~mm}$. $/ 1 \mathrm{hr}$., serum alkaline phosphatase $16 \mathrm{~K}$.-A. units, fasting blood glucose $286 \mathrm{mg}$. $/ 100 \mathrm{ml}$. Treatment was started with 40 units daily of soluble insulin, but while the diabetes was controlled, the abdominal pain and distension increased. A plain radiograph on 15 July showed a dilated colon (Fig. 1a), and sigmoidoscopy revealed a granular rectal mucosa with copious bloodless mucopus coming from above. The provisional diagnosis was acute proctocolitis, with toxic megacolon, though the sigmoidoscopic findings were not wholly typical. At operation the bowel from the hepatic flexure to the upper sigmoid was engorged and dilated. A double-barrelled defunctioning ileostomy was constructed. Over the next few weeks the patient's condition was critical. The diabetes was unstable, there was severe wound infection and collapse of the left lung base, and a large abscess developed over the sacrum. In addition to insulin, she received antibiotics, blood transfusions and instillations of prednisone into the distal limb of the ileostomy. A barium enema on 21 August (Fig. 1b) revealed that the previously dilated segment of bowel was now shrunken and stenosed; sigmoidoscopy at this time was normal to $18 \mathrm{~cm}$. Aortography on 3 September (Fig. 1c) showed no middle colic artery and no anastomosis between the superior and inferior mesenteric systems at the splenic flexure.

On 10 September, the affected bowel was removed, and the proximal limb of the ileostomy joined to the rectosigmoid. The post-operative recovery was uneventful. Microscopically, the excised bowel showed mucosal ulceration and patchy replacement of all layers with vascular granulation tissue and fibrosis (Fig. 9).

This patient has now been followed up for one year. She leads a normal life, the diabetes is controlled, and she passes two or three soft formed motions daily.

TRANSIENT ISCHAEMIC COLITIS (CASE 14) An obese woman, aged 50, was seen as an out-patient at St. Thomas's Hospital on 27 June 1963 with a history of sudden left-sided abdominal pain six weeks previously, which had been followed by the passage of bright blood and clots per rectum on three occasions. There were no 


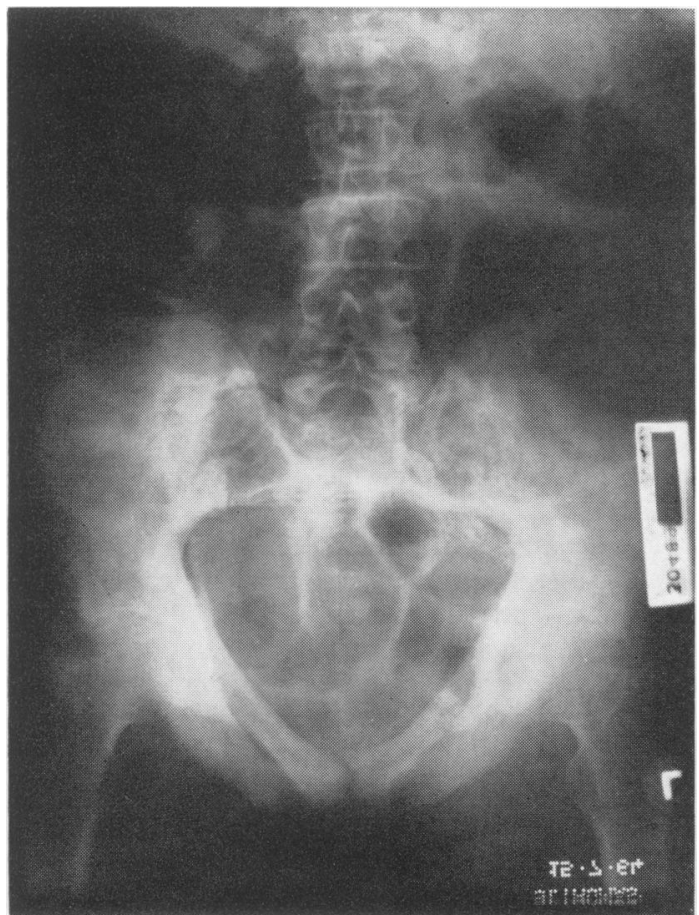

FIG. 1a. Case 5: Plain film of abdomen immediately before operation. physical signs on examination, apart from tenderness in the left iliac fossa, and sigmoidoscopy was normal, but a barium enema showed that there was a ragged area in the descending and sigmoid colon (Fig. 2a) with obvious 'thumb printing' (Boley et al., 1963). No treatment was advised other than a reducing diet, and her symptoms did not recur. The enema was repeated on 14 December 1963 and this time showed no abnormality (Fig. 2b). She was reviewed for a further year and remained well until her final discharge from the clinic on 31 December 1964. She has recently written to say that she is well.

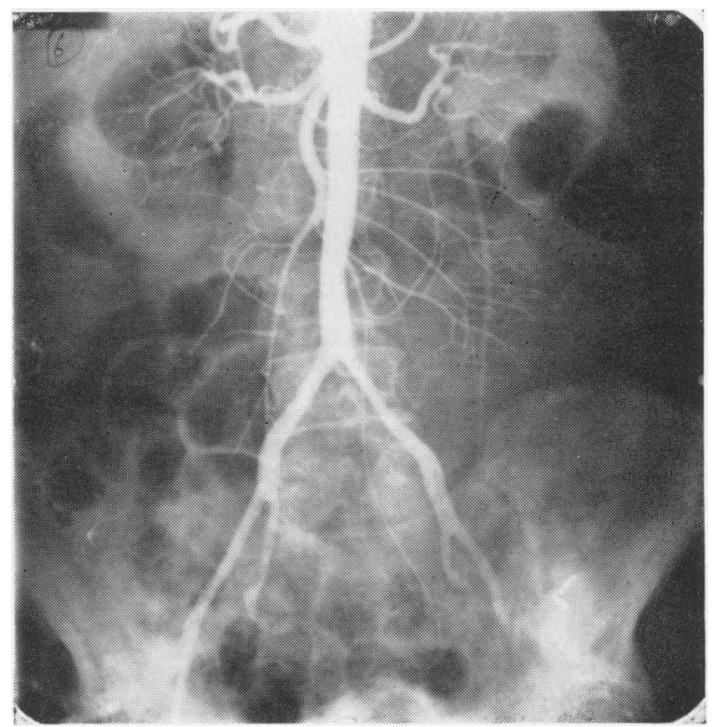

FIG. 1c. Aortogram.

\section{RADIOLOGY}

MATERIAL AND METHODS Of the 16 patients in this series 14 underwent radiological investigation. All have had an initial barium enema performed from 10 days to three months after the onset of symptoms and in three follow-up examination were undertaken. In 11 cases the barium enema films are available for study and in the three others the site and some of the features of the lesions shown are indicated by radiologists' reports. In addition to the barium enema, plain films of the abdomen were taken in one patient and in two aortography was performed by Seldinger's technique. The patients not investigated radiologically were the case of ischaemic colitis with gangrene, who presented as a grave emergency, and one patient with an ischaemic stricture who came to operation before investigation.

FINDINGS The plain films of the abdomen in the only patient in whom they were obtained showed generalized dilatation of the colon, suggesting acute

FIG. 1b. Barium enema five weeks after ileostomy. 


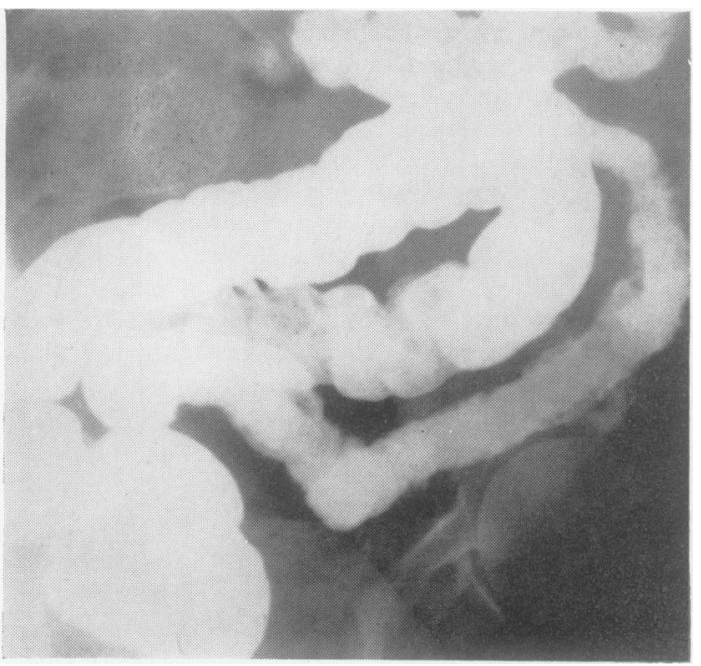

FIG. $2 \mathrm{a}$.

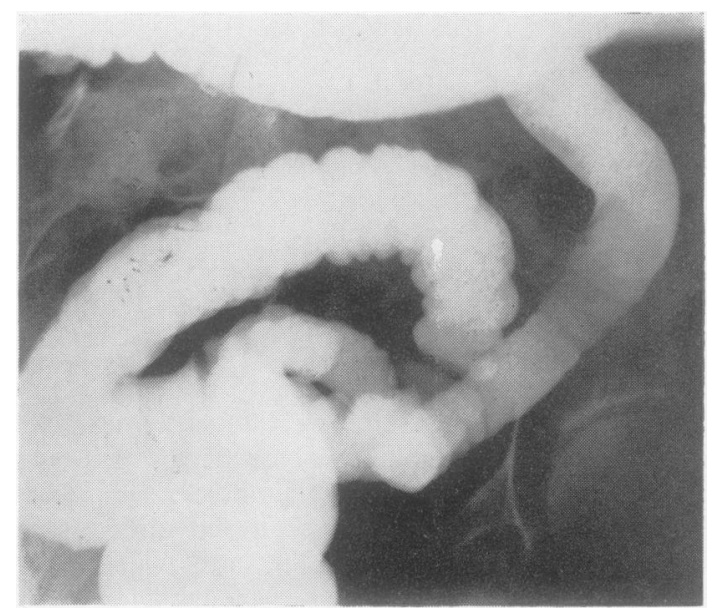

FIG. 2 b.

FIG. 2a. Case 14: Six weeks after the acute episode, showing thumb printing and mucosal irregularity.

FIG. 2b. Three months later. Normal. toxic dilatation of proctocolitis (Fig. 1a). The barium enema performed later showed that the colon had narrowed to form a long stricture (Fig. 1b).

The barium enema was abnormal in all cases in the present series in which it was performed and the appearances are similar to those described by Boley et al. (1963), Schwartz, Boley, Lash, and Sternhill (1963), Marshak et al. (1965), and Irwin (1965). The essential abnormality has consisted of a stricture characteristically involving the splenic flexure. The lesion occurred at this site to a greater or lesser degree in 12 of the 14 cases, the lesion in the other two cases being in the sigmoid colon and in the descending colon. In no case was the rectum abnormal radiologically.

The length of the stricture varied from a few centimetres to involvement of the whole of the transverse and descending colon. The degree of narrowing also varied from slight to almost complete obstruction. There was loss of haustration and some shortening of the affected segment. As a rule the stricture was clearly demarcated from the adjacent normal colon.

When the stricture is examined in detail four types of abnormality have been noted: 'thumb printing' (Boley et al., 1963), ragged 'saw-tooth' irregularity of the mucosa, tubular narrowing, and sacculation.

Thumb printing is a polypoid change giving a scalloped margin to the bowel wall with translucent rounded filling defects extending into the lumen in the filled phase of the barium enema, and showing as soft tissue masses in the air-barium doublecontrast films (Fig. 3). Sacculation consists of shallow, wide-mouthed, out-pouchings or pseudodiverticula of the colonic wall (Figs. 6a and b).

The most common abnormality encountered has been a combination of two or more of the above changes (Fig. 1b and Fig. 4), although thumb printing, mucosal irregularity, and tubular narrowing have each been seen alone. Generally thumb printing and mucosal irregularity have been seen early in the disease and sacculation and tubular narrowing at a later stage but one short stricture was present only a month after the onset of symptoms (Fig. $5 \mathrm{a}$ and $b$ ). In this series the most constant radiographic signs have been thumb printing and sacculation, features which we believe are the most suggestive of ischaemic colitis.

In the three patients with transient ischaemic colitis, repeat examinations a few weeks after the initial barium enema showed that two had returned to normal (Figs. 2a and b) and one was left with a mild, smooth narrowing. In the remaining cases classified as ischaemic stricture, repeat barium enemas were not carried out because resection became necessary. 


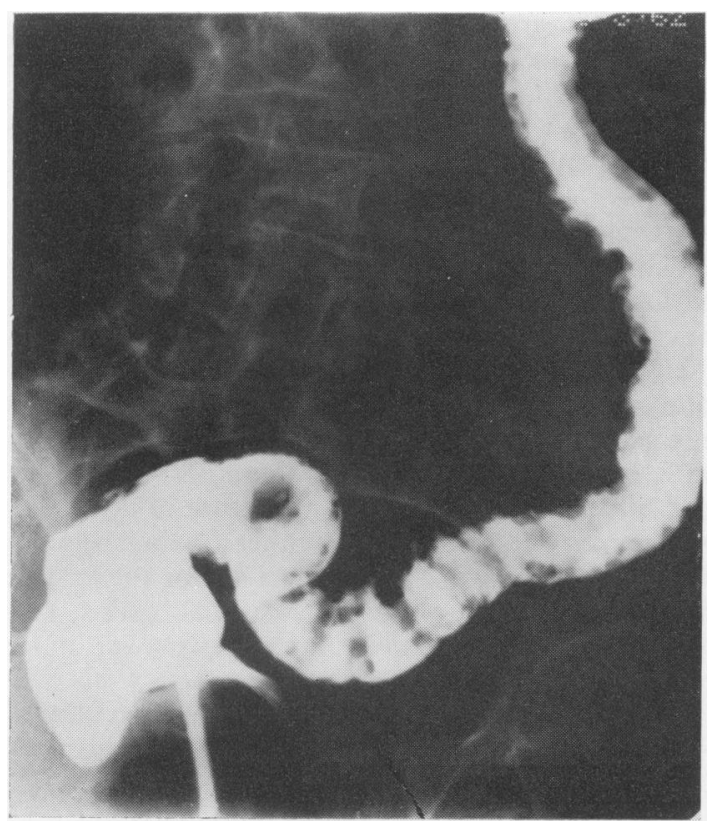

FIG. 3.

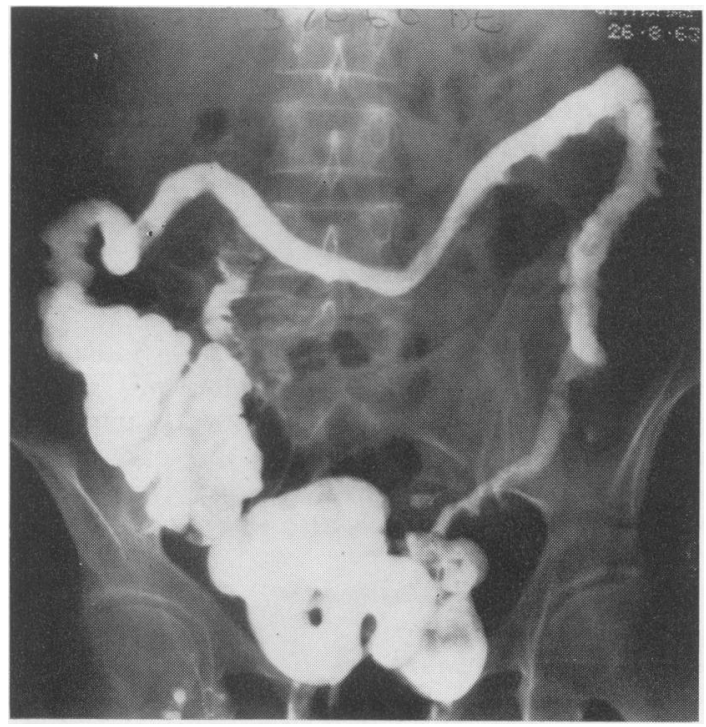

FIG. 4.

FIG. 3. Case 3: Thumb printing.

FIG. 4. Case 13: Ischaemic stricture. Note tubular narrowing and sacculation.

FIG. 5. Case 8: Localized ischaemic stricture: (a) barium enema and (b) the excised specimen.

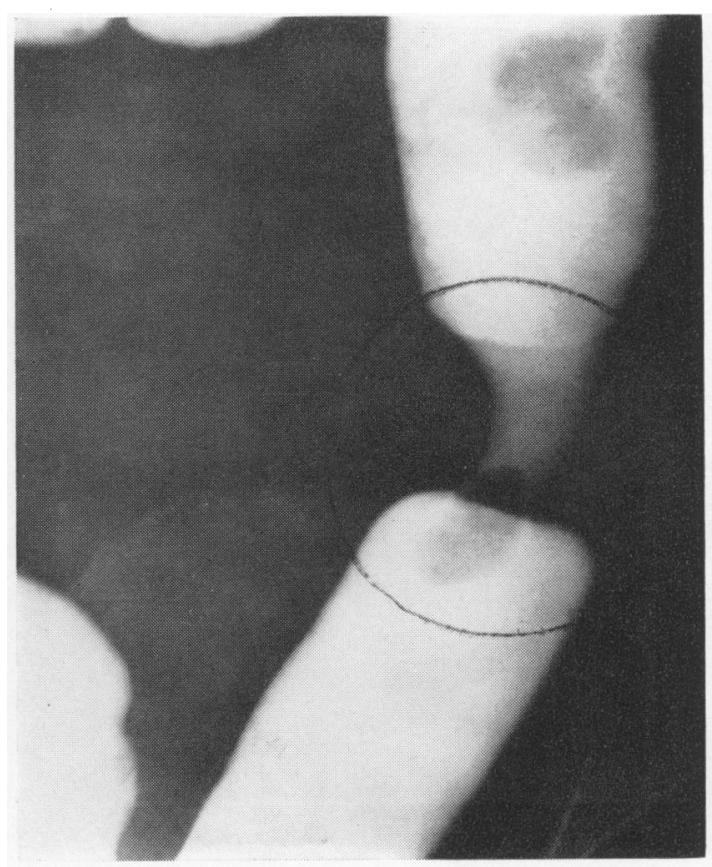

FIG. 5a.

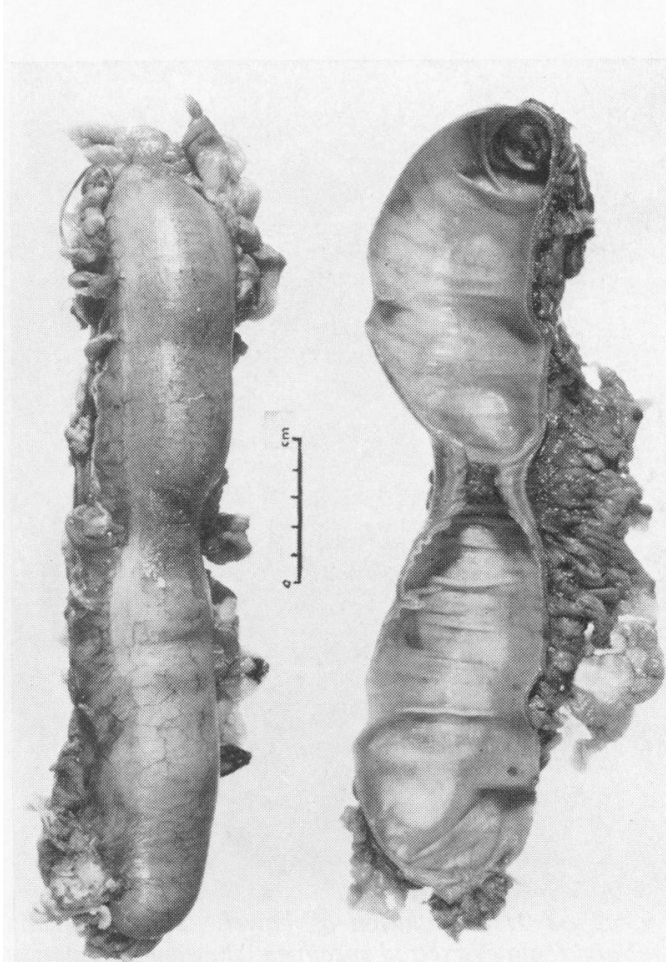

FIG. 5b. 

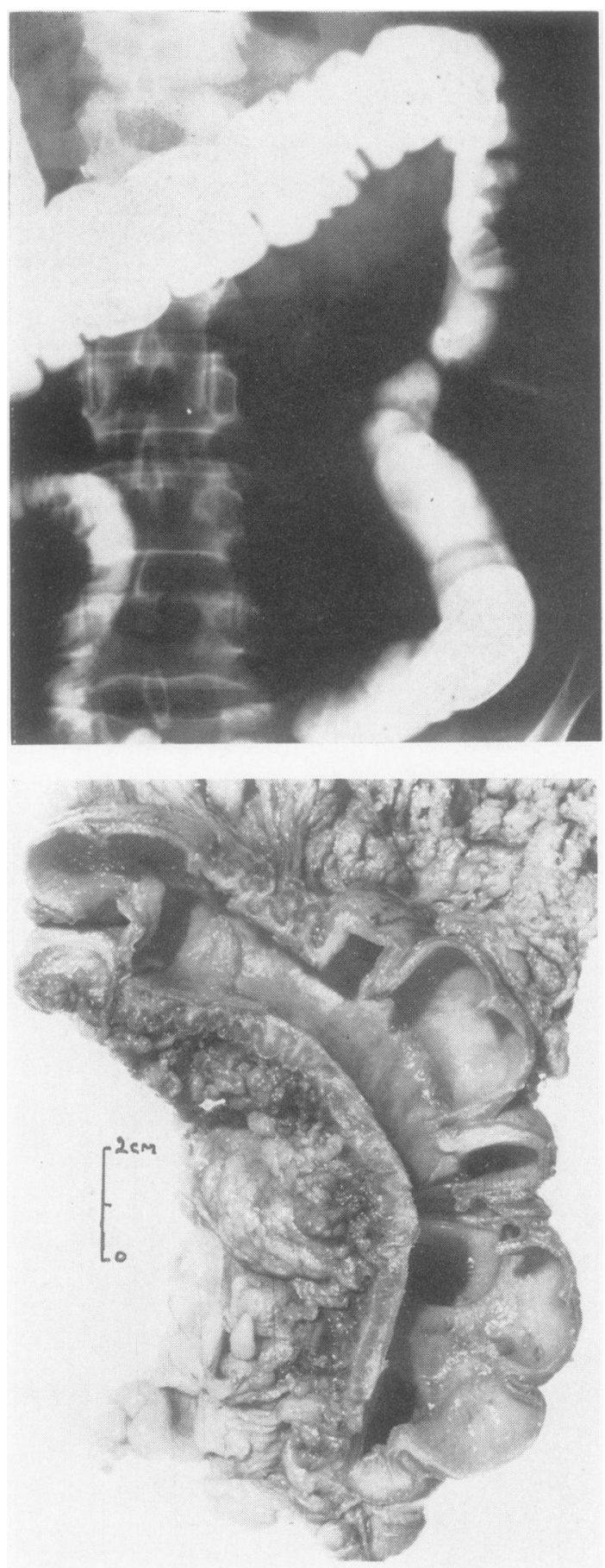

FIG. 6. Case 9: Sacculation of bowel. Barium enema (above) and (below) excised specimen, showing sacculation of the bowel wall particularly on the antimesenteric aspect. Patchy mucosal ulceration (not well shown) on the mesenteric aspect where thickening is also considerable.
The aortograms in the two cases in which they were performed showed in one an occluded middle colic artery and in the other an absent middle colic artery with a poor marginal artery in the region of the splenic flexure (Fig. 1c).

DIFFERENTIAL DIAGNOSIS The main conditions from which ischaemic colitis has to be distinguished on barium enema examination are Crohn's disease and carcinoma. Typically in transient ischaemic colitis the changes regress without specific treatment. The site of the lesion may be helpful. The rectum is affected in $50 \%$ of cases of Crohn's disease and in $95 \%$ of cases of proctocolitis (Lockhart-Mummery and Morson, 1964), whereas in no case of this series was the rectum abnormal. Neither Crohn's disease nor carcinoma have any predilection for the splenic flexure, the common site for ischaemic colitis, and the changes in proctocolitis are usually much more extensive.

Of the radiographic signs described, sacculation is not seen in Crohn's disease, proctocolitis, or carcinoma. Thumb printing and mucosal irregularity may resemble the ulceration and inflammatory polyposis of acute proctocolitis and also the 'cobblestone' appearance of Crohn's disease. The progression of the changes in proctocolitis to uniform narrowing, loss of haustration, and shortening is not seen in ischaemic colitis. Involvement in Crohn's disease is as a rule more patchy than in ischaemic colitis and the deep linear ulceration or 'spiking' have not been observed in the latter condition.

Carcinoma is only likely to be confused with the short ischaemic stricture which may be very like an annular neoplasm. In carcinoma, however, 'halfshadowing' can often be made out, indicating extension of the neoplasm into the lumen.

It may not be possible to make a firm diagnosis of ischaemic colitis in every case on radiological appearances alone, but this can usually be achieved when the clinical picture is also taken into account.

\section{PATHOLOGY}

MACROSCOPIC APPEARANCES The one case in this series classified as infarction of the bowel with gangrene (case 1) showed a thickened and actively inflamed peritoneal aspect with several small bulges of gangrenous appearance. On opening the specimen the gangrene appeared more extensive and confluent, particularly in the distal transverse colon. There was considerable mucosal oedema. All the other cases in which the macroscopic appearances were studied showed a varying extent of stricture formation with mucosal ulceration. In two specimens 
there was a short fusiform type of stricture (Fig. 5b) with sharp demarcation between the normal and ulcerated mucosa at either end. In a further two cases there was a similar short fusiform stricture, but patchy, superficial, and longitudinal ulceration of the mucosa extended for a short distance above and below its limits, and in two others the stricture was longer and irregular with a striking sacculation of the gut wall on its antimesenteric aspect (Fig. 6b). Mucosal ulceration was patchy, serpiginous, mainly longitudinal, and situated principally on the mesenteric aspect. The remainder of the specimens showed extensive tubular strictures with considerable thickening of the gut wall and narrowing of the lumen. The submucosa, in particular, was widened and the mucosa ulcerated over most of the strictured zone. Other features in the macroscopic appearance included peritoneal adhesions and fibrosis, which were most obvious in the specimens with extensive tubular strictures. Enlargement of the regional nodes was not a noticeable feature. There was no inflammatory polyposis, 'cobblestoning' of the mucosa, or other features suggestive of Crohn's disease or proctocolitis.

MICROSCOPIC APPEARANCES In the exceptional case of infarction and gangrene (case 1) the appearances were identical to those reported by McGovern and Goulston (1965) in their specimens of ischaemic enterocolitis. Theirs, however, was a post-mortem study of severe and extensive disease at an early stage of development when intravascular thrombi, mucosal haemorrhage, and oedema are characteristic. In the remainder of the specimens the changes were essentially those of a resolving inflammation. They were recognizably different from those seen in idiopathic proctocolitis, in Crohn's disease, or other types of 'colitis.'

The principal features of resolving ischaemic colitis are full-thickness loss of mucosa in the ulcerated areas, the surface of which is covered by granulation tissue packed with dilated capillary blood vessels. At the edge of ulcerated areas epithelial regeneration is present with columnar

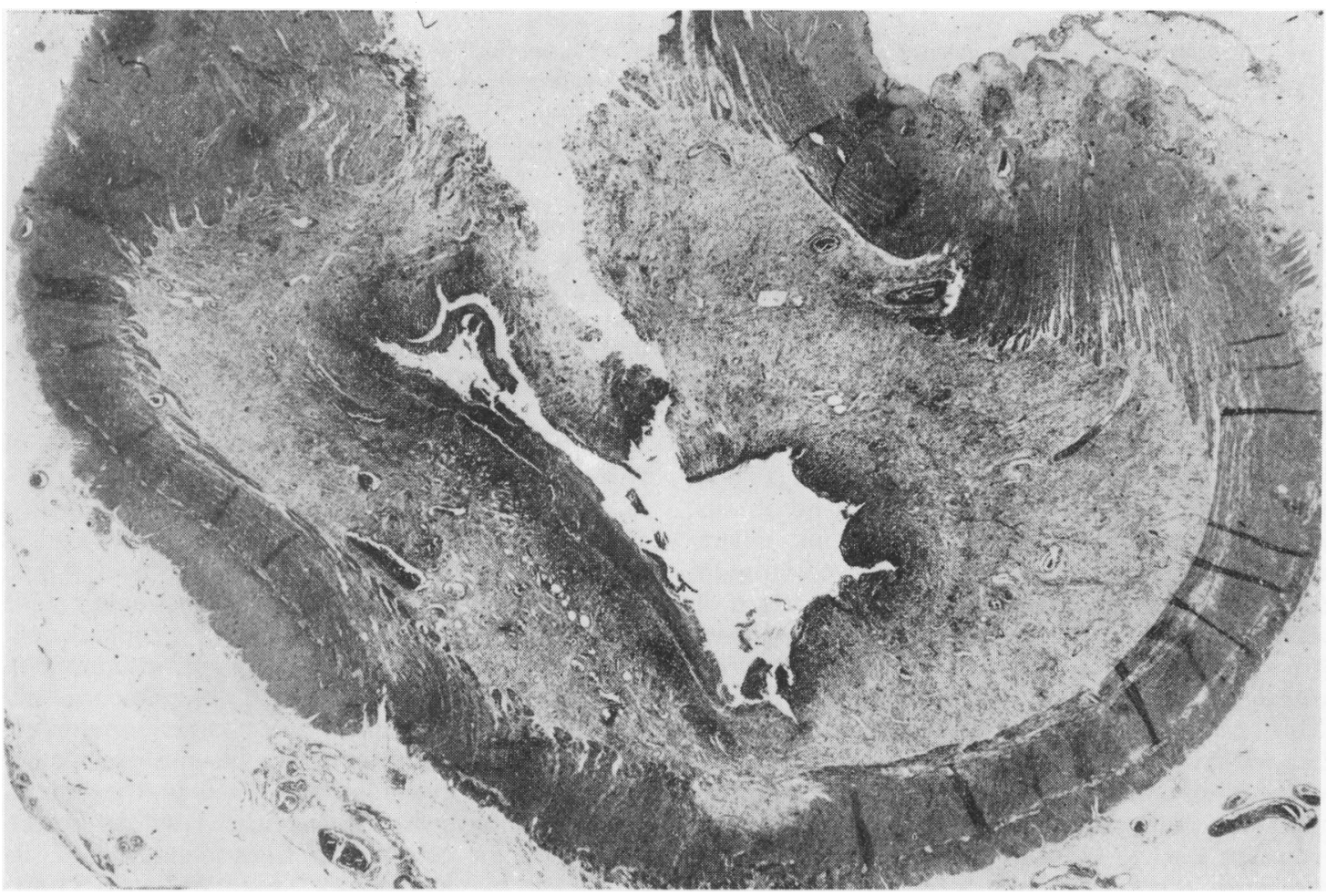

FIG. 7. Transverse section of the gut wall to show mucosal ulceration and widening of the submucosa which is filled with granulation tissue. There are also patchy changes of similar character outside the muscularis propria. Haematoxylin and eosin $\times 8$. 


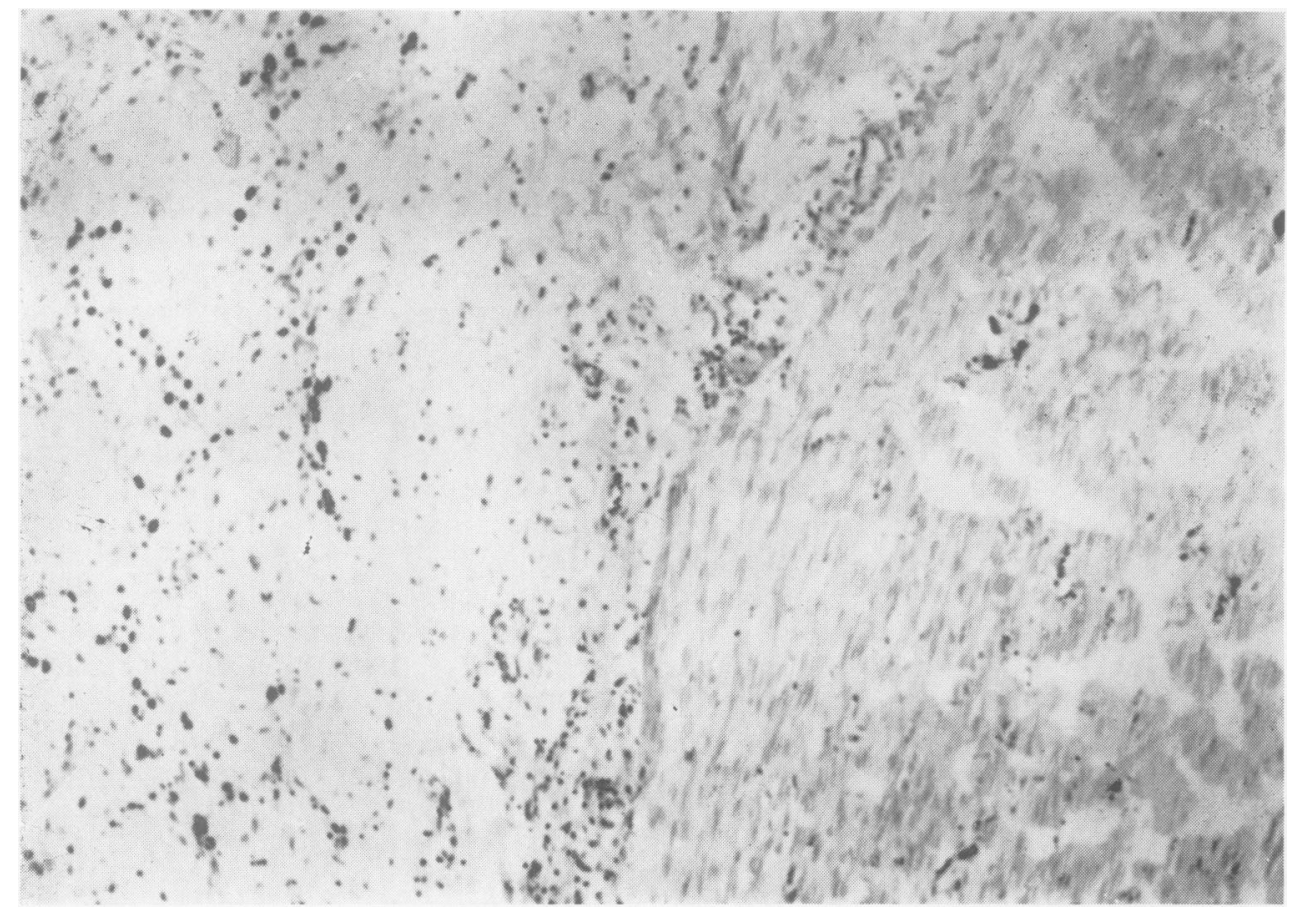

FIG. 8. Section of submucosa and deep muscle laver of bowel wall stained by Perl's Prussian blue method for haemosiderin. Numerous macrophages, which appear black in the photograph, are scattered throughout the tissues. Haematoxylin and eosin $\times 260$.

epithelium beginning to grow over the surface. Neighbouring intact mucosa is not always normal but shows patchy atrophy and irregularity of structure suggestive of a healed state with incomplete recovery. The muscularis mucosae adjacent to ulcerated areas appears damaged with splaying of its fibres and fibrosis. The submucosal layer shows the most conspicuous changes, being widened and filled with a characteristic granulation tissue (Fig. 7). This consists of marked proliferation of fibroblasts, some oedema, and a sprinkling of chronic inflammatory cells, including lymphocytes, eosinophils, and plasma cells. There is also an increase in collagen. Many macrophages full of pigment, giving the staining reaction for haemosiderin, are a prominent feature of the cellular infiltrate (Fig. 8). (This observation is probably of considerable diagnostic importance as identical cells are a feature of the granulation tissue of the resolving inflammation in ischaemic myocarditis.) The submucosal arterioles tend to be thick-walled and tortuous. In two cases there was quite a prominent fibrinoid necrosis in the wall of some of the submucosal vessels near the surface of ulcerated bowel but this was probably a secondary arteritis. The muscularis propria showed patchy fibrosis with replacement and separation of its fibres by granulation tissue identical and continuous with that seen in the submucosal layer (Fig. 9). The inflammatory process also involved the serosa and pericolic tissues, but this is always patchy.

The whole histological picture of this stage of ischaemic colitis strongly resembles the appearances in the resolving stage of ischaemic myocarditis (Mallory, White, and Salcedo-Salgar, 1939; LodgePatch, 1951) and is distinct from the microscopic pathology of idiopathic proctocolitis or Crohn's disease. Transmural hyperplasia of lymphadenoid tissue, intramural fissuring, and sarcoid granulomata are conspicuously absent. Crypt abscesses are only occasionally seen and inflammatory polyposis is not a feature. Moreover, haemosiderin-laden macrophages have not been noted in the inflammatory infiltrate of proctocolitis. A special search was made for colonies of Clostridium welchii, as described by Killingback and Williams (1961) and Tate, Thompson, and Willis (1965), but these were not found. 


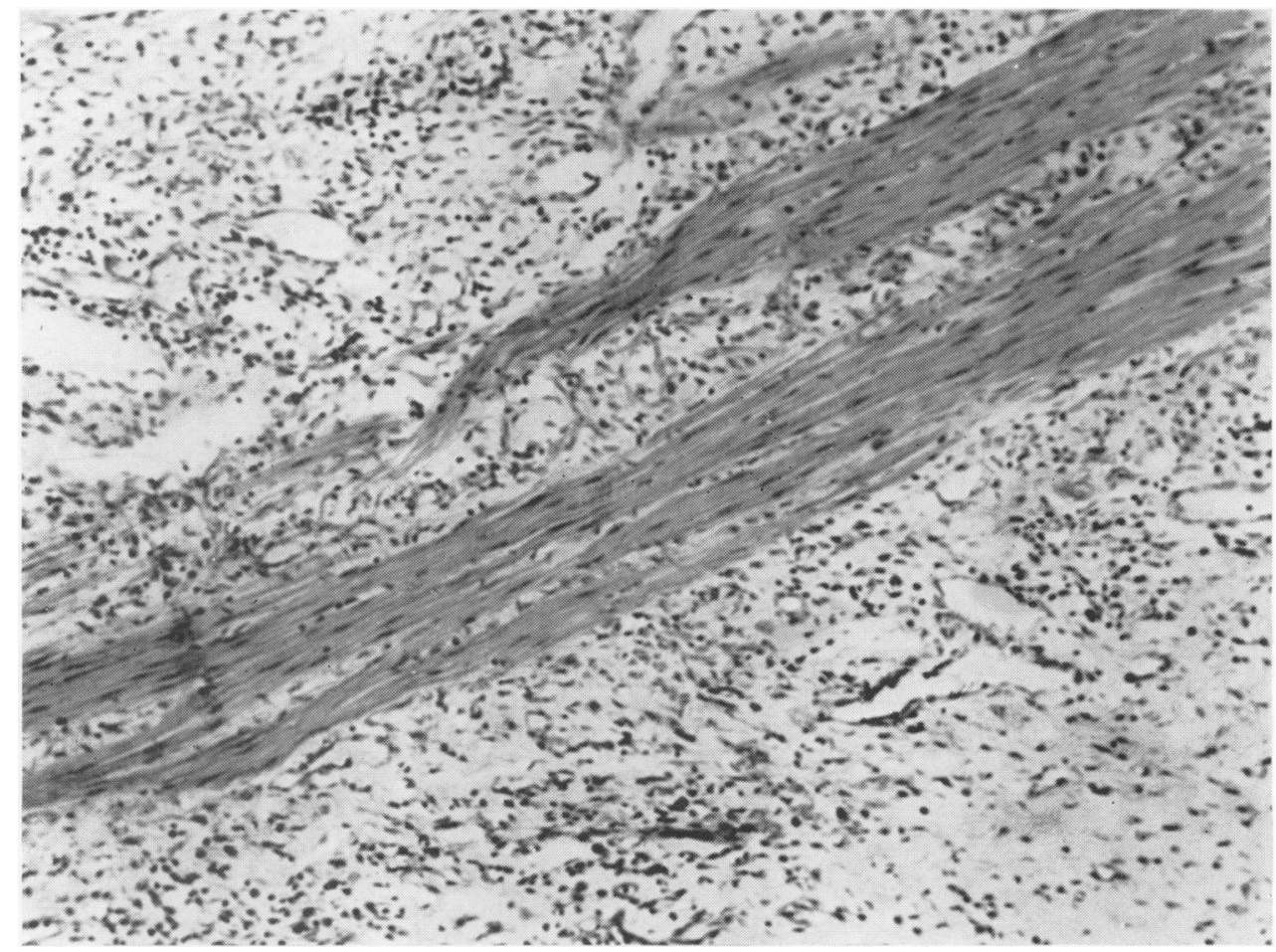

FIG. 9. Transmural replacement of the gut wall by inflammatory granulation tissue with destruction and separation of the fibres of the muscularis propria. Haematoxylin and eosin $\times 120$.

\section{DISCUSSION}

Reports by other workers (see Fig. 10) suggest that ischaemic colitis is not rare although it has been given a number of different names. In most instances the authors have felt that their cases showed unusual manifestations of ulcerative colitis or Crohn's disease. On clinical grounds this seems to us unlikely, because an older age group is affected, the illness is acute and self-limiting, and a sharply localized area of colon is involved which never includes the rectum. There are no ileal lesions or 'skip areas', and the anal ulceration present in $80 \%$ of cases of colonic Crohn's disease (Lockhart-Mummery and Morson, 1964) is never found. Moreover, the radiological and pathological appearances are distinctive.

In two of our cases a blocked or absent colonic vessel was demonstrated on aortography and in a third case a mesenteric embolus had occurred. The pathological appearances of those three cases in which the vascular abnormality was proven were identical to the others in which it was suspected. The age incidence is consistent with that expected in degenerative vascular disease. The site of the lesion is at the point where the superior and inferior mesenteric systems inosculate and the blood supply is precarious (Griffiths, 1956). In the past a similar bowel lesion has been demonstrated following arterial occlusion (Thomson, 1948; Engelhardt and Jacobson, 1956; Cooling and Protheroe, 1958; McCort, 1960; Marshak et al., 1965), and it has been produced in dogs by ligation of the inferior mesenteric artery (Boley et al., 1963). On these grounds, and from the additional clinical evidence discussed below, we conclude that this syndrome is the result of infarction. When the colon is exposed at operation it often appears hyperaemic from dilatation of the collateral supply. This is in fact a haemorrhagic infarct, which explains why rectal bleeding is such a constant feature.

It is quite understandable that sudden deprivation of blood supplying a region of the colon should result in a stricture but in our series we have not, except in cases 2, 5, and 12, demonstrated a major vascular block, because aortography was not performed, either because the ischaemic nature of the lesion was not suspected before laparotomy or because the examination was considered unjustifiable in patients already recovering. (We believe that useful information could be obtained in future cases by selective arteriography of the superior and 


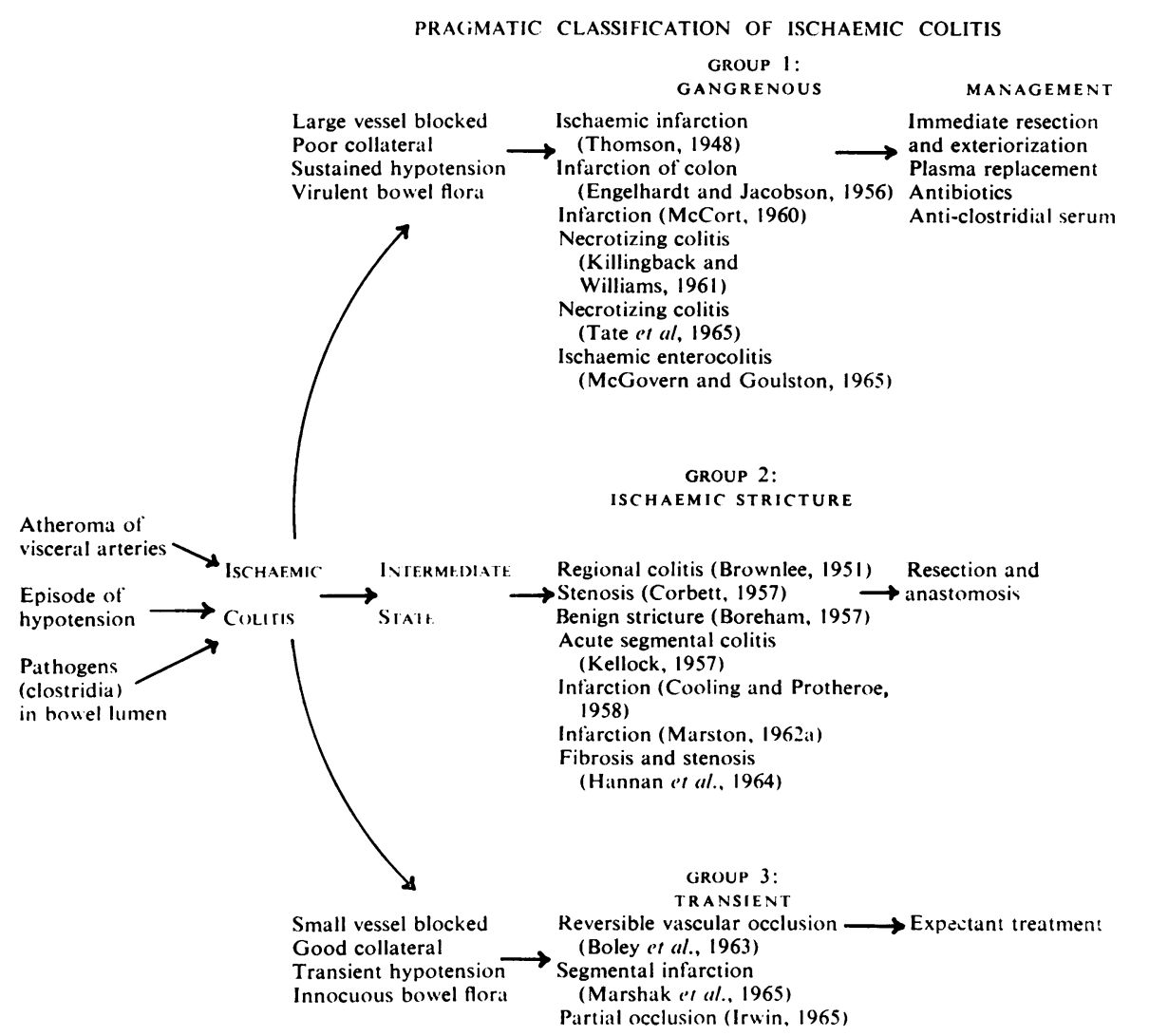

Low mortality

No mortality but possible recurrence

inferior mesenteric systems, since this would influence the time and nature of surgery.) A normal arteriogram, however, does not exclude the diagnosis.

It is important to realize that the blood supply to both the small and large intestine can suddenly fail even though the major vessels remain patent (Berger and Byrne, 1961; Marston, 1962b), and a histological infarct may occur without the demonstration of a vascular block (Lister and Jungmann, 1956; Engelhardt and Jacobson, 1956; Cooling and Protheroe, 1958). Atheromatous plaques at the origin of the three main visceral arteries are common at this age, and small fluctuations in blood pressure across such lesions can result in shut-down of the peripheral vessels and ischaemic change in the bowel (Marston, 1962b). To invoke this mechanism in all cases of ischaemic colitis would be an oversimplification, and other factors, such as vascular spasm and local vascular reflexes, focal Schwartzman reactions, congenital abnormalities of the vessels, mechanical obstructions, and rheumatoid arteritis undoubtedly operate. Thus, two patients in this series had a previous history of rheumatoid arthritis and a third developed florid rheumatoid joints a few weeks after the colitis subsided. In one of these patients marked arteritis was seen histologically. It is very likely that rheumatoid vasculitis of the bowel (Hingorani and Graham, 1963) may account for some cases of localized ischaemic colitis.

\section{CLASSIFICATION OF ISCHAEMIC COLITIS}

From a study of previously reported examples and of our present material, it appears that there are three types of ischaemic colitis, corresponding to the three degrees of ischaemia outlined in our introduction, and we propose the pragmatic classification shown above. It is inevitably an arbitrary one because we are describing differences in degree and timing of the same disease process, and individual features may overlap, but it is useful as a guide to management.

GROUP 1 : ISCHAEMIC COLITIS WITH GANGRENE (CASE 1) Gangrene of the colon has been described following ligation of a major colic artery (Lauenstein, 1882; Dzialoswynski, 1925), following a thrombosis (Ferguson, 1932; Gambee, 1937; Huggard and 
Herstein, 1948; Thomson, 1948; Johnson and Baggenstoss, 1949; McCort, 1960), or an embolus, (Brown and Dey, 1932), and as a complication of aortic reconstruction (Smith and Szilagyi, 1960; Young, Humphries, de Wolfe, and Lefevre, 1963). It presents as a fulminating abdominal catastrophe with gross depletion of the plasma volume and endotoxaemia, and is almost always fatal. McGovern and Goulston (1965) have described 33 cases of fulminant enterocolitis associated with ischaemia, due to a combination of hypotension and atheroma of the mesenteric vessels. The majority of their patients had advanced cardiac disease, as did our case 1 and those reported by Berger and Byrne (1961).

Occasionally this gangrenous type of colitis appears to be associated with clostridial invasion (Killingback and Williams, 1961; Tate, Thompson, and Willis, 1965). Although there is no doubt that the presence of pathogenic clostridia contributes to the speed and severity of bowel necrosis, it is difficult to see how such organisms, which are normal commensals in $35 \%$ of the population (Dudgeon, 1926), gain access to the deeper layers unless the mucosal defences are broken down. It is difficult to avoid the conclusion that in such cases an underlying vascular deficiency permits the invasion of incidentally present Clostridia, which then contribute to the rapid onset of gangrene.

Group 1 cases clearly require immediate operation, resection and exteriorization. In view of the part that pathogenic Clostridia may play, it would seem wise to give massive doses of penicillin and polyvalent antiserum at the same time. The mortality is very high and likely to remain so (McGovern and Goulston, 1965).

GROUP 1: ISCHAEMIC STRICTURE (CASES 2 TO 13) Twelve of our cases presented with a history of abdominal pain and rectal bleeding, and with physical or radiological signs that made operation necessary (see case 5 above). Essentially, the lesion in these patients was a rapidly developing stricture in the neighbourhood of the splenic flexure. Such strictures have been recognized for some time and have generally been described as 'segmental colitis' (Butler, 1953; Neuman, Bargen, and Judd, 1954; Manning, Warren, and Adi, 1955). Brownlee (1951) reported three cases of 'regional colitis' presenting as emergencies, all of which showed strictures in the region of the splenic flexure. Kellock (1957) described eight further patients, every one of whom gave the typical history of pain, bleeding, and stricturing in this position. Boreham (1957) described seven cases of 'benign stricture of the colon' occurring in middle-aged or elderly patients, and again mainly around the splenic flexure. All of these presented acutely, had no radiological features suggestive of proctocolitis, and histologically showed inflammatory cell infiltration and fibrosis. Boreham (1957) discusses the causation of the lesion in some detail but does not mention ischaemia as a possibility. Later authors, however (McCort, 1960; Hannan, Jackson, and Pipik, 1964), have used the term infarction.

These cases, which are the majority, are treated by resection of the strictured bowel with either primary anastomosis or exteriorization, depending on circumstances. Patients who present as emergencies are best not subjected to a one-stage anastomosis, because the extent of the infarct is uncertain and the suture line may lie in an ischaemic area. However, those who attend after the acute episode has subsided do well with an elective one-stage reconstruction following pre-operative cleansing of the bowel. From our own and others' experience the prognosis seems excellent: the operative mortality is low and the infarction does not usually recur. At the same time, thought should be given to the underlying abnormality which produced the ischaemic episode, particularly the possibility of a lesion at the origin of the superior mesenteric artery, and if this is causing symptoms it should be reconstructed, because of the danger of eventual small bowel necrosis (Marston, 1964).

GROUP 3: TRANSIENT ISCHAEMIC COLITIS (CASES 14 To 16) Boley et al. (1963) describe a series of five patients presenting with acute abdominal pain and rectal bleeding, which subsided without specific treatment, and in whom the barium enema showed 'thumb printing'. If followed by serial barium enema examination, these lesions clear up completely. Boley was able to reproduce the appearances in dogs by occlusion of the inferior mesenteric artery, and in one of his cases the sigmoidoscopic findings and biopsy confirmed ischaemia (Carter, Vannix, Hinshaw, and Stafford, 1959). Marshak et al. (1965) describe a similar case in which the underlying vascular lesion was proven to be a thrombosis of the inferior mesenteric artery. Like Boley et al. (1963), Schwartz et al. (1963), Marshak et al. (1965), and Irwin (1965) we have observed reversibility of the lesion shown on the barium enema, either to complete normality or to the formation of a smooth stricture (Fig. 2). Of three patients in whom follow-up examinations were undertaken in the first weeks or months of the disease, two had returned to normal and one was left with a smooth stricture. In these cases 'thumb printing' or mucosal irregularity had been present exclusively or predominantly at the initial examination. In two patients in this group laparotomy was not necessary. In the third the abdomen was 
explored and a thickened area around the splenic flexure was biopsied. The appearances were consistent with resolving ischaemic colitis.

Group 3 cases may be expected to resolve and are treated symptomatically with antispasmodic drugs and a mild mechanical laxative. Serial barium enemas should be performed every three months until the bowel has reverted to normal, to make sure that the stricture is not neoplastic. With increasing experience, it is likely that more patients will be managed in this way. For instance, the symptoms in case 9 (see Fig. 6) were mild and some improvement was noticed on a second barium enema. Resection was advised because the ischaemic nature of the stricture was not realized, and for this reason we have placed the patient in group 2 . However, if operation had not been carried out there might have been continued improvement and eventual resolution and the case would then have been reasonably classified as 'transient ischaemia'. On the other hand, six patients from our own and previous series have had an episode of transient ischaemia which has later recurred and produced a fibrous stricture. The prognosis in this group therefore, is optimistic but guarded.

These are the patients who are liable to be treated with corticosteroids, which will have no effect on the colonic lesion, and carry dangers of their own. It is bad practice to give steroids to cases of colitis whose aetiology is uncertain.

\section{SUMMARY}

The clinical features, radiology, and pathology of 16 patients with ischaemic colitis are described.

The main clinical features are sudden abdominal pain and rectal bleeding with signs of left-sided peritonitis. One patient developed gangrene of the colon; 12 developed a stricture in the region of the splenic flexure; and three recovered without resection of gut. On the basis of post-clinical and experimental work a classification of ischaemic colitis into gangrenous, stricturing, and transient forms is proposed.

The barium enema in all cases, except the one with gangrene of the colon, showed strictures with four characteristic signs which may or may not coincide. These are 'thumb printing', 'saw-tooth irregularity' of the mucosa, tubular narrowing, and sacculation. The differential diagnosis from idiopathic proctocolitis (ulcerative colitis), Crohn's disease, and carcinoma is discussed.

The macroscopic and microscopic pathology of ischaemic colitis is described. Excepting the one case of gangrene of the colon, all the surgical specimens showed stricture formation with mucosal ulceration and widening of the submucosa, which is filled with a characteristic granulation tissue. Many haemosiderin-laden macrophages are a prominent feature of the cellular infiltrate.

The management of the three types of ischaemic colitis is described. Gangrene of the colon is best treated by replacement of blood volume, antibiotics, a polyvalent antiserum, and excision of the necrotic bowel with exteriorization of the ends. Ischaemic strictures can usually be treated by one-stage resection and anastomosis. Transient ischaemia requires no special treatment but serial barium studies must be performed until the bowel has returned to normal.

It is suggested that ischaemia of the colon, occurring in the same age group and from the same causes as myocardial infarction, accounts for some cases of 'segmental' colitis, particularly those involving the splenic flexure.

We wish to thank the physicians and surgeons of St. Thomas's Hospital, St. Mark's Hospital, and St. Peter's Hospital, Chertsey, for permission to publish cases admitted under their care. Dr. J. R. Tighe, Dr. T. D. Kellock, Dr. C. F. Ross, and Dr. J. F. Arthur kindly provided us with pathological material, and Dr. A. C. Young with radiographs.

We are grateful also to the staffs of the Photographic and Medical Illustration Departments of the Middlesex, St. Thomas's, and St. Mark's Hospitals, and in particular to Mr. H. Sibson Drury, Mr. T. W. Brandon and Mr. Norman Mackie for work on the illustrations, and to Mr. Lloyd Soodeen for preparation of sections.

Case 12 was originally reported in the British Journal of Surgery (1962) and is included here with the Editor's permission.

\section{REFERENCES}

Berger, R. L., and Byrne, J. J. (1961). Intestinal gangrene associated with heart disease. Surg. Gynec. Obstet., 112, 529-533.

Boley, S. J., Schwartz, S., Lash, J., and Sternhill, V. (1963). Reversible vascular occlusion of the colon. Ibid., 116, 53-60.

Boreham, P. (1957). Benign strictures of the colon. Proc. roy. Soc. Med., 50, 601-604.

Brown, P., and Dey, M. M. (1932). Gangrene due to embolus of the inferior mesenteric artery. Brit. med. J., 1, 186-187.

Brownlee, T. J. (1951). Regional colitis as an acute abdominal emergency. Brit. J. Surg., 38, 507-513.

Butler, E. C. B. (1953). Surgical management of certain granulomata of the intestine. Proc. roy. Soc. Med., 46, 69-74.

Cameron, G. R., and Khanna, S. D. (1959). Regeneration of the intestinal villi after extensive mucosal infarction. J. Path. Bact., 77, 505-510.

Carter, R., Vannix, R., Hinshaw, D. B., and Stafford, C. E. (1959). Inferior mesenteric vascular occlusion: sigmoidoscopic diagnosis. Surgery, 46, 845-846.

Cooling, C. I., and Protheroe, R. H. B. (1958). Infarction of the colon. Postgrad. med. J., 34, 494-499.

Corbett, R. (1957). Stenosed segment of descending colon associated with trauma. Proc. roy. Soc. Med., 50, 271-272.

Dudgeon, L. S. (1926). A study of the intestinal flora under normal and abnormal conditions. J. Hyg. (Lond.), 25, 119-141.

Dzialoswynski, A. (1925). Gangrän des Colon transversum. (Erstmalige Beobachtung einer geheilten Falles.) Zbl. Chir., 52, 2120-2122. 
Engelhardt, J. E., and Jacobson, G. (1956). Infarction of the colon, demonstrated by barium enema. Radiology, 67, 573-575.

Ferguson, C. D. (1932). Gangrene due to embolus of the inferior mesenteric artery. Brit. med. J., 1, 840-841.

Gambee, L. P. (1937). Occlusion of the inferior mesenteric vessels. West. J. Surg., 45, 105-112.

Glotzer, D. J., Villegas, A. H., Anakayama, S., and Shaw, R. S. (1962). Healing of the intestine in experimental bowel infarction. Ann. Surg., 155, 183-190.

Griffiths, J. D. (1956). Surgical anatomy of the blood supply of the distal colon. Ann. roy. Coll. Surg. Engl., 19, 241-256.

Hannan, J. R., Jackson, B. F., and Pipik, P. (1964). Fibrosis and stenosis of the descending colon and sigmoid following occlusions of the inferior mesenteric artery. Amer. J. Roentgenol., 91, 826-832.

Hingorani, K., and Graham, G. S. (1963). Small-bowel necrosis due to arteritis in rheumatoid disease. Ann. phys. Med., 7, 68-71.

Huggard, R., and Herstein, A. (1948). Thrombosis of the inferior mesenteric artery. Canad. med. Ass. J., 62, 502-503.

Irwin, A. (1965). Partial infarction of the colon due to reversible vascular occlusion. Clin. Radiol., 16, 261-263.

Johnson, C. C., and Baggenstoss, A. H. (1949). Mesenteric vascular occlusion: II. Study of 60 cases of occlusion of arteries and of 12 cases of occlusion of both arteries and veins. Proc. Mayo Clin., 24, 649-656.

Kellock, T. D. (1957). Acute segmental ulcerative colitis. Lancet, 2, 660-663.

Killingback, M. J., and Williams, K. L. (1961). Necrotizing colitis. Brit. J. Surg., 49, 175-185.

Klein, E. (1921). Embolism and thrombosis of the superior mesenteric artery. Surg. Gynec. Obstet., 33, 385-405.

Lauenstein, C. (1882). Ein unerwartetes Ereignis nach der Pylorusresektion. Zbl. Chir., 9, 137-141.

Lister, E., and Jungmann, H. (1956). Gangrene of the colon. Brit J. Radiol., 29, 341-343.

Lockhart-Mummery, H. E., and Morson, B. C. (1964). Crohn's disease of the large intestine. Gut, 5, 493-509.

Lodge-Patch, I. (1951). The ageing of cardiac infarcts, and its influence on cardiac rupture. Brit. Heart J., 13, 37-42.

Mallory, G. K., White, P. D., and Salcedo-Salgar, J. (1939). The speed of healing of myocardial infarction. Amer. Heart J., 18, 647-671.
Manning, J. H., Warren, R., and Adi, A. S. (1955). Segmental colitis: results of surgery. New Engl. J. Med., 252, 850-853.

Marshak, R. H., Maklansky, D., and Calem, S. H. (1965). Segmental infarction of the colon. Amer. J. dig. Dis., 10, 86-92.

Marston, A. (1962a). Massive infarction of the colon demonstrated radiologically. Brit. J. Surg., 49, 609-611.

- (1962b). The bowel in shock. Lancet, 2, 365-370.

- (1964). Patterns of intestinal ischaemia. Ann. roy. Coll. Surg. (Engl.), 35, 151-181.

McCort, J. J. (1960). Infarction of the descending colon due to vascular occlusion. New Engl. J. Med., 262, 168-172.

McGovern, V. J., and Goulston, S. J. M. (1965). Ischaemic enterocolitis. Gut, 6, 213-220.

Neuman, H. W., Bargen, J. A., and Judd, E. S., Jr. (1954). A clinical study of two hundred and one cases of regional (segmental) colitis. Surg. Gynec. Obstet., 99, 563-571.

Niederstein, K. (1906). Die Zirkulationstorugen im Mesenterialgebiet. Dtsch. Z. Chir., 85, 710-778.

Pope, C. H., and O'Neal, R. M. (1956). Incomplete infarction of ileum simulating regional enteritis. J. Amer. med. Ass., 161, 963-964.

Reeves, J. D., and Wang, C. C. (1961). The stages of mesenteric artery disease. Sth. med. J., 54, 541-548.

Schwartz, S., Boley, S., Lash, J., and Sternhill, V. (1963). Roentgenologic aspects of reversible vascular occlusion of the colon and its relationship to ulcerative colitis. Radiology, 80, 625-635.

Smith, R. F., and Szilagyi, D. E. (1960). Ischaemia of the colon as a complication in the surgery of the abdominal aorta. Arch. Surg., 80, 806-821.

Tate, G. T., Thompson, H., and Willis, A. T. (1965). Clostridium Welchii colitis. Brit. J. Surg., 52, 194-197.

Thomson, F. B. (1948). Ischaemic infarction of the left colon. Canad. med. Ass. J., 58, 183-185.

Varga, A. T., and Currie, D. J. (1965). Inferior mesenteric vascular occlusion. Canad. J. Surg., 8, 87-92.

Wang, C. C., and Reeves, J. D. (1960). Mesenteric vascular disease. Amer. J. Roentgenol., 83, 895-908.

Wolf, B. S., and Marshak, R. H. (1956). Segmental infarction of the small bowel. Radiology, 66, 701-707.

Young, J. R., Humphries, A. W., de Wolfe, V. G., and Lefevre, F. A (1963). Complications of abdominal aortic surgery. Arch. Surg., 86, 51.59. 